\title{
Seizing the Moment: \\ A Blueprint for Reform of World Cricket
}

\author{
Ian Preston* \\ University College London \\ Stephen F. Ross \\ University of Illinois at Urbana-Champaign \\ Stefan Szymanski \\ Imperial College Management School
}

(November 2000, revised June 2001)

JEL Classification: L83, K49

Keywords: Sport, cricket, reform, corruption

Abstract

We argue that the current match-fixing crisis in world cricket has its origin in the economic structure of the game. Cricketers' pay is demonstrably low relative to sports of comparable significance and this is a consequence of the organisation of the game with its emphasis on international representative cricket. We propose and outline details of an international club championship with competition for players' services.

* Corresponding author: Ian Preston, Dept of Economics, University College London, Gower St, London WC1E 6BT (Email: i.preston@ucl.ac.uk) 


\section{Introduction: The current crisis and its solution}

The crisis in cricket threatens the future of the oldest organised team sport ${ }^{1}$. The revelations of the King Commission (King 2000) in South Africa included the admission by the former South African captain, Hansie Cronje, that he had accepted bribes for fixing matches and suborned the corruption of other team members. The Qayyum Report (Qayyum 1998) in Pakistan found the former Pakistani captain, Salim Malik, to have fixed matches and reported a failure to cooperate with its enquiry by another former captain, Wasim Akram, among others. The investigation by the Central Bureau of Investigation of the Indian Police Force (CBI 2000) pointed to extensive corruption involving among others the former Indian captain, Mohammed Azharuddin, and also alleged the improper involvement of other international players, including former England, West Indies, Sri Lanka and New Zealand captains and players of Australia $^{2}$, with bookmakers. Most recently, the report (Condon 2001) of the investigation commissioned by the governing body of world cricket, the International Cricket Council (ICC), and led by the former UK Metropolitan Police Commissioner, Sir Paul Condon, has failed to draw a line under the current scandals. Referring to a "climate of silence, apathy, ignorance and fear," the comprehensive report suggests evidence of continuing corruption. All of this has seriously undermined the credibility of the international game.

In the short term it is clear that cricket has to deal with the cheats. Given the relatively small number of genuine stars in the game, this process will inevitably prove difficult. The reluctance of national cricket boards to take decisive and immediate action against alleged culprits, even where they have admitted talking to bookmakers, highlights the dilemma of the authorities. Wedded to a not unnatural concern to retain those stars that draw the crowds, there is also genuine sympathy for individuals whose careers may have been distinguished and whose lapses may by comparison have been minor.

In the longer term, there is need to reform the structure of the international game to ensure that the conditions that encouraged cheating to flourish are eliminated. In this paper we argue that the fundamental problem is the meagre financial rewards received by the top international cricketers. Condon $(2001$, p.33) is explicit in acknowledging poor pay of cricketers as a leading candidate explanation for the spread of corruption. Moreover, press reports suggest that this view has already been accepted by some senior figures in the cricket hierarchy. The chairman of the MCC, Lord Alexander of Weedon, reportedly called for cricketers to be paid more so that they are less likely to be tempted by match-fixing offers (BBC website, 17 November 2000). However the response of the England and Wales Cricket Board shows that acceptance is not widespread: "The England and Wales Cricket Board has noted the remarks reportedly made by MCC President, Lord Alexander of Weedon, that international cricketers should be paid more so that they are less likely to be tempted by offers to be involved in match-fixing. The ECB Management Board takes the view that the pay of many international cricketers has increased significantly in recent times and they are now well rewarded for their skill and expertise and that, in any event, there is no justification for any international cricketer to succumb to corruption. (ECB Press Release 18 November 2000)" We believe high salaries would be a significant disincentive to cheating, as we believe it is in most other

\footnotetext{
${ }^{1}$ Most team sports were not formally organised until the nineteenth century, while the rules of cricket were written down in 1744 (Birley 1999).

${ }^{2}$ On Australian players' involvement with bookmakers, see O'Regan (1998).
} 
major sports. The incentive to cheat is increased when there is an imbalance between the financial status of the players and the financial returns to the sport as whole. In cricket the top players earn a much smaller fraction of the total revenues generated by their efforts than is the case in other major international sports.

Low pay for international cricketers is the consequence of an organisational structure that uses the revenue from popular international matches to subsidise domestic competitions and that undermines the bargaining position of top players over pay. Removing the cross-subsidy might provide a temporary respite, but since competitions are not capable of generating enough income to cover costs they would have to be severely curtailed. This in turn would limit the supply of new talent coming into the game and hence undermine its long term future.

We believe that there is an alternative way to deal with the underpayment of professional cricket players. In most sports outside of North America income and thereby professional salaries are boosted by the existence of international club competitions that complement the international representative game. The introduction of international club cricket would in our view add a significant dimension to international cricket that would command spectator and media attention. Competition among international clubs for the best players would be a sure way to bid up the salaries of international cricketers. Such a competition could operate alongside and sustain the integrity and durability of a flourishing Test game.

\section{Cheating in Sport}

Cheating in sports falls into two categories. On the one hand, when the rewards for winning dwarf the rewards for coming second, third or lower, the incentive of participants is to use every means possible to win. This can lead to a damaging competition among athletes to take performance enhancing drugs and adopt potentially harmful therapies in the search for excellence. This problem, a consequence of the "winner-take-all" reward structures encouraged by newspapers and media, sponsors and advertisers is most obvious in the Olympic sports where many believe that illegal doping is rife. However, all the major sports have struggled to control the use of performance enhancing drugs and cricket has not stood out as a sport suffering particularly extreme problems in this regard.

The second form of cheating is the one we are concerned with here. It is the reverse of the "winner take all" dilemma. If the rewards to athletes are inadequately differentiated, then there is an incentive for those athletes who are good enough to exert a disproportionate influence on the outcome of a contest to use that power to enhance their income, largely through gambling. This is likely to be exacerbated in sports such as cricket where the individualistic nature of the conflict creates opportunities for betting on performance of particular players ${ }^{3}$. Of course, when athletes' incomes are undifferentiated, it is normally because they are all very low. Match fixers are only interested in sports that command significant public interest. Match fixing in recondite sports such as curling is probably a limited problem even though the best curlers probably make very little money.

Most sports can cite examples of this problem. Perhaps the most famous example is that of "Shoeless Joe" Jackson and the 1919 Black Sox scandal. Jackson, who held the second

\footnotetext{
${ }^{3}$ Condon (2001, p.31) points to a wide range of imaginative ways in which players have been alleged to have fixed occurrences within matches for betting purposes - including control of fielding positions, ends of the pitch from which bowling commences and so on.
} 
highest lifetime batting average in baseball (.354) at that date was earning a mere $\$ 6,000$ a year (less than $\$ 50,000$ in today's money), unquestionably a small reward compared to the attendance income generated by his efforts. The desire to enhance his income by throwing the World Series was his undoing. An example from English soccer illustrates the same point. In 1965 ten players were jailed for conspiracy to defraud by fixing the outcome of matches on which they had placed bets. Most of the matches concerned took place in the early 1960s, when the average footballer earned less than $£ 20$ per week which was in fact the maximum wage allowed until its abolition in 1961. The history of cricket has itself not been without instances of corruption of poorly paid players by bookmakers, with instances particularly well attested in the eighteenth century (see Birley 1999, Craig 2001, and especially Underdown 2000).

Match fixing may be motivated by activities other than gambling. In particular, when one team not in contention for a championship title can influence the outcome by it performance, side-payments or non-monetary arrangements are not unknown. Condon (2001, pp.27-8)) suggests that the "seeds" of the current crisis may have been sown in the atmosphere created by "accommodations" of this kind in the 1970s. However, in any case of match fixing, the fundamental elements of supply and demand must balance. From the point of view of the "buyer", fixing matches is generally only important when there is a high degree of interest in the sport and so a significant return is to be made by controlling the outcome, usually for the purposes of gambling. The potential match fixer must have the capacity to significantly influence the outcome, so that in general only the stars are likely to be approached. On the "selling" side, the players must balance the reward from fixing against the potential cost of being caught. This cost is the probability of being caught multiplied by the penalty for fixing. In almost all sports the most draconian penalty available to authorities is deprivation of sporting income by exclusion from participation in the sport. Raising salaries of the top players is therefore the main way of raising the penalty to cheating.. Moreover raising salaries is also likely to diminish the attractiveness of additional illicit income. To put it simply a player on $\$ 100,000$ a year would find a bribe of $\$ 100,000$ very much more attractive than the same player earning $\$ 1,000,000$ a year ${ }^{4}$.

High salaries do not eliminate all forms of cheating, and do not even eliminate match fixing. In particular, if the controllers of the sport are themselves unable to extract a significant proportion of the consumer surplus associated with the sport, then match fixing may be hard to prevent. For example, if $90 \%$ of the money spent on the sport is in the form of gambling, while only $10 \%$ is generated through the sale of match tickets and broadcast rights, the rewards that someone interested in controlling the outcome of a match or a race may be well in excess of any reward that the event organiser can offer. Any sport that becomes a vehicle for gambling where the gamblers have only a limited interest in the sport itself is at risk. However, high salaries make match fixing less enticing for most players, and means that those players committed to cheating can be more easily detected since they are a relative minority of the profession.

\footnotetext{
${ }^{4}$ If we take exclusion from the sport as the penalty then the bribe required to corrupt a player needs to make the expected utility under corruption no less than that under honesty. Excluding, for simplicity and without affecting the nature of the argument, considerations of shame and scruples we need $(1-p) U(y+B)+p U(B)-U(y)=0$ where $y$ is sporting income, $U($.$) is utility, p$ is probability of detection and $B$ is minimal bribe required. The standard assumption of risk aversion implies that $B$ increases with $y$.
} 


\section{Causes of the cricket crisis and the need for a new competition}

It is plain that corruption has made headway in cricket to an extent far greater than other sports of comparable significance. At the level of individual players, no-one would deny that "greed and opportunity" - the factors stressed by Condon (2001, p.35) - are the main factors in explaining why one cricketer will have succumbed to temptation while another will not. However this is inadequate as an explanation for why the sport as a whole should have been so vulnerable. Rather than suggest that cricketers as a whole have a greater tendency to venality of character than other sportsmen, we would argue that the proven susceptibility of the sport to corruption is a product of the incentives provided to them by the economic structure of the sport.

Cheating in cricket can to a significant degree be attributed to the remarkably low rewards that international test match cricketers can earn. According to the published accounts of the England and Wales Cricket Board (ECB 1999) English cricket generates an income of around $£ 50 \mathrm{~m}$ in a typical year and in the recent World Cup year made over $£ 80 \mathrm{~m}^{5}$. A recent threeyear TV deal was said to be worth about $£ 150 \mathrm{~m}$. However, the central contracts offered by the ECB to its international players are typically worth something of the order of $£ 150,000$ per year ${ }^{6}$, leaving the entire squad with less than $10 \%$ of the final take through contracted payments. The principal reason that the clubs receive such a small proportion of the final take is the need to subsidise the domestic game of county cricket. County cricket is a game mostly played over four days, mostly during the working week and so few people can attend, and often those that can attend are on low incomes (for example, pensioners). The counties simply cannot fund their own expenses, even when the average player receives a wage of only around $£ 30,000$. Cross subsidies from the ECB are therefore essential if any young players are to be raised through the county ranks to a Test Match standard. In 2001 each county received about $£ 1.275 \mathrm{~m}$ from the ECB.

Much the same can be said of the game in other countries. In Australia, currently the dominant nation in world cricket, the Australian Cricket Board has predicted gross cricket related income averaging about $\mathrm{A} \$ 100 \mathrm{~m}$ per year over the next four years. The highest paid current contracted Australian player can not earn more than A $\$ 625,000$ though the prospect of pay rising to $\mathrm{A} \$ 1 \mathrm{~m}$ from 2004 has been mooted. These figures are very low when compared to other major world sports. In North America the minimum salaries of major league players negotiated by the player unions are in region of US\$250,000 per year (although most journeyman players are likely to earn little more than this). But these are not the stars whom the bookmakers would generally set out to tempt. Stars earn much more- for example in 1998 there were over 50 baseball players who started the season with salaries in excess of US $\$ 5 \mathrm{~m}$ about twenty times the minimum salary. Even allowing for the fact that there is much more money in North American sports, cricket salaries are significantly out of line when it comes to the gap between the highest and lowest. A similar story can be told for soccer, where top players will earn many times the salary of the average journeyman. Even in rugby union, which is far less wealthy than soccer or North American sport, top stars can now earn many times the basic wage earned by the regular club player.

\footnotetext{
5 "Turnover in 1999 amounted to $£ 83,7212,000$ (1998 - £50,733,000) including $£ 48,030,000$ in respect of the 1999 World Cup (p.4)".

${ }^{6}$ The England cricket captain is believed to earn a higher figure of around $£ 250,000$. By comparison the England soccer captain is thought to earn about $£ 5 \mathrm{~m}$ (though through his club salary rather than payments for his international role).
} 
Of course, players can earn more than the basic salaries mentioned here because of sponsorship and endorsement deals. Top stars in cricket can earn an annual income many times in excess of the basic retainer. Furthermore, even within cricket, Test Match players can receive bonuses and other rewards related to performance. But even if the test star earns 10 times their annual retainer, it must be remembered that a player's career is relatively short and the post career income is highly uncertain. Few cricketers could expect to achieve career earnings in excess of $£ 1 \mathrm{~m}$, a sum well below the expected lifetime earnings of even a moderately talented accountant. Cronje's admission that he had accepted US $\$ 10,000$ to throw a game was as striking for the smallness of the sum (for which, among other misdemeanours, a glittering career was sacrificed) as for its proof of his moral frailty ${ }^{7}$. Could anyone imagine Michael Jordan or Ronaldo accepting such a small sum to throw a game?

Why do players accept these low rewards? The answer must lie in the dominance of the international representative game in cricket. National eligibility rules prevent competition between teams for the services of players, removing the most potent means for players to bid up their salaries. Recent years have seen several high profile contractual disputes between players and authorities over rates of pay - a symptom perhaps of discontent over the weak position of players.

The root of the problem therefore lies in three observations:

(a) International players receive only a small fraction of the income generated by their playing activities- as little as $10 \%$ compared to the average of around $50 \%$ common in most professional team sports.

(b) The ratio between the salaries of the best international players and journeyman cricketers - typically less than 2:1 compared to more than 20:1 in most professional team sports

(c) Cricket relies almost exclusively on international representative cricket to generate income - club, state or county level income contributes almost nothing.

Our solution lies in solving problem (c) and using the money generated by our solution to solve problems (a) and (b). Domestic competition is hampered not only by the fact that cricket takes a long time to play and a significant fraction of playing time occurs during working hours (baseball to a degree suffers from the same problem). Most domestic matches are not attractive because only a relatively small number of stars appear in the matches. The top players are spread thinly around a large number of teams, and so that in any given match only a few such players participate. Furthermore the best British county players frequently spend most of their time off on Test duty - even more so with the introduction of central contracts. A club level competition that could generate significant income would have to create a situation where top players regularly faced each other as they do at the international representative level. To achieve this we propose the creation of a new international club competition. This would not replace existing domestic competitions, which are a necessary breeding ground for young talent, but would add an extra tier of club level competition. This competition could involve as few as eight different clubs, based in the major international cricket centres around the world.

These elite clubs would then compete for the services of the top cricket stars- there would be no restrictions on nationality, and perhaps even a requirement to hire foreign players. In this

\footnotetext{
${ }^{7}$ The meagreness of the sums allegedly paid to induce corrupt practice are striking - see, for example, Bose (2001).
} 
way an active market would be created for services of the stars, a market which is currently missing. As long as the competition in which these clubs participated attracted widespread interest, the clubs that were bidding for the services of the top players would be capable of paying high salaries. In this way the top stars would come to hold a significant financial stake in the development of the game and the likelihood of accepting small bribes to throw matches would diminish. Of course, this scheme can not guarantee the end of corruption in cricket, and even the wealthiest sportsmen could be open to large enough bribes, but our view is that a thriving international club competition to match the interest in Test Match cricket would not only help to discourage corruption, but would also stimulate interest in the game.

It would be important to coordinate the organisation of such a competition with schedules for Test cricket. The aim is not to challenge the central importance of international five day cricket but to reform other aspects of the game so as to enhance its robustness. The decision of the ICC to endorse a league table for international Test cricket is an important step to contextualise and thereby strengthen interest in Test match competition. The new competition being proposed here would be a limited overs game and in order to avoid unacceptable additional pressure on players' workloads we would propose that it be arranged in conjunction with a diminution in the number of other one day international games ${ }^{8}$. Condon (2001, p.34) follows others in pointing to the "large number of One Day Internationals" in which "nothing is really at stake" as a contributory factor in the willingness of cricketers to accept corrupt offers. The growth of the international one day game has occurred largely through a proliferation of small tournaments widely acknowledged to suffer from limited memorability. A club competition of the sort outlined here would be well designed to encourage commitment in one day international cricket, to the general benefit of the game. We would envisage the World Cup remaining as the pinnacle of the one day international game but with a significance enhanced by the reformed context in which it would occur ${ }^{9}$.

\section{The demand for a new competition}

We propose the creation of a new international club cricket competition to run alongside Test Match cricket (the most distinguished form of the international representative game). The scope for a new competition is difficult to gauge without a detailed feasibility study, but there are several indicators which suggest that the scope exists. First, perhaps is the notable success of the "World Series Cricket" organised by Kerry Packer, owner of Australian Channel 9, at the end of the 1970s. This breakaway competition was created because Packer was dissatisfied with the Test Match broadcasting deal on offer and therefore he hired the top international stars to play a series of "international" matches. The players received considerably higher salaries to participate in the venture, and the Series introduced a number of important innovations such as night cricket. While Packer ultimately abandoned World Series Cricket after reaching agreement with the cricket authorities, its success with the public in Australia was unquestioned. Our argument is that this kind of "all-star" competition is potentially more interesting to cricket fans than domestic competitions. The sheer number of teams and matches in domestic competition is worth documenting, since it is this fragmentation that limits the scope for interesting competitions.

\footnotetext{
${ }^{8}$ There may be problems with existing broadcasting contracts. However if broadcasters agree that the reform will generate interest the rights to broadcast the new competition will offer a profitable attraction.

${ }^{9}$ This can be compared to the position in other sports such as football where international representative competitions, such as the World Cup or European Championship, mark an acknowledged high point in the game while most international competition remains at club level.
} 


\section{(a) Existing domestic competition}

Each of the major cricket nations operate to a different system. This in itself prevents the creation of something like a "Champions' League" which is superimposed on domestic competition in European soccer. In Rugby Union, the need to create an international club competition in southern hemisphere, the Super-12's obliged the national rugby competitions to be significantly restructured.

\section{(i) England}

The England season currently runs from mid April to mid September. The 18 first class cricket counties are now divided into two divisions (9 teams each), with promotion and relegation. Teams participate in two leagues- a four day match competition and one-day (Sunday) tournament. In addition there are two Cup competitions played at different stages of the season and which also involve counties below the first class level (in one competition).

\section{(ii) Australia}

The season runs from October to March. Australia has narrowed down the variety of competition and number of teams at the first class level to a far greater degree. Thus competition operates at the State level, involving only six teams. Moreover, there are only two main competitions, the Pura Cup for the 3-day game and the Mercantile Mutual Cup for the one-day game.

(iii) India

The season runs from May to February. The main competitions are the Ranji Cup and the Ranji One-Day Cup, which involve 23 teams, mainly representing the states (although there are some others such as the Indian Railways team). The teams are divided into 5 zones, with zonal champions progressing to a set of play-offs to produce an overall national champion.

(iv) Pakistan

The season runs from mid-October to January. There are two main competitions, the Quaid-eAzam Trophy and the Patron's Trophy. These are played at first and second class levels. The Patron's Trophy first grade involves 9 teams divided into two groups playing both one-day and four-day matches. The Quaid-e-Azam Trophy involves 12 teams in two divisions playing four-day matches leading to a final played between the winners of each division.

\section{(v) South Africa}

The South African season runs from October to March. There are 11 first class teams representing the provinces of South Africa, and they play in three main tournaments. The Super Sports Series consists of four-day matches, the Standard Bank Series consists of oneday matches and the UCB Bowl involves both three and one-day matches. 
West Indies cricket is complicated by the fact that the region is not a single country, although they play as a single unit at Test Match level. The "domestic" season runs from October to March. The main competitions are the Red Stripe Bowl (including the USA and Canada) which is one day competition based around ten teams in two zonal divisions and the Busta Cup, which is a four-day competition involving Barbados, Guyana, Jamaica, Windward Islands, Trinidad \& Tobago, Leeward Islands, Trinidad, England 'A' and West Indies 'B'.

In total therefore there appear to be in the region of seventy first class teams in world cricket, most of whom play during the southern hemisphere summer. These figures do not include the teams based in other cricketing nations such as New Zealand, Sri Lanka and Zimbabwe. While the progression from southern hemisphere summer to northern hemisphere summer enables many of the top players to play all year round if they sign contracts with English counties, the fact remains that cricket boasts far more "first class" teams than any north American sport, and even in Europe it would be hard to argue that there were more than fifty top rank soccer clubs. Given that there is probably a smaller supply of top class cricketers than top class athletes in these other sports, and that the diffusion of these contests spreads the spectator base very thinly, it seems reasonable to suppose that there could be a significant gain to focusing the interest of cricket fans on a narrower range of tournaments and clubs. Whereas soccer, as the dominant international sport, can survive with a fragmented range of competitions, sports such as cricket and rugby, with their smaller revenue base, need to focus the interest of the fans.

\section{(b) Population, income and city sizes}

A successful international club competition will have to satisfy two essential requirements- it must be small enough to ensure that the top stars are regularly pitted against one another, and it must be spread among the largest cricketing nations in order to ensure the maximum degree of fan interest, indeed partisanship. Most cricket nations struggle if say, their top three batsmen or top three bowlers are injured - suggesting that there are probably few more than a hundred international cricket stars able to compete at the highest level. Assuming that teams require squads of at least fifteen players, this suggests the supply of international standard cricketers would support a league of no more than eight to ten teams. A league of this size would bring the top players consistently into opposition with one another, and ensure that almost every match contained some exciting confrontations. In essence, the number of clubs should more or less replicate the number of competitive cricketing nations, which again implies somewhere in the region of eight to ten teams.

One weakness of the World Series Cricket was its location in Australia- it was viewed by the other cricketing nations as a largely Australian affair, even if the teams themselves were essentially national teams. In part this reflected the broadcasting arrangements of the competition, which limited the resale of the championship internationally (with digital TV there can be little doubt that the rights could be sold to somebody in the UK, for instance, even if the dominant broadcasters were not interested). To draw the analogy with soccer again, the Italian Serie A is very successful and widely considered the strongest league in the world because of the presence of so many foreign stars, but its viewership figures outside of 
Italy are negligible compared to genuinely international tournaments such as the Champions League.

We suggest that there are two options for geographical organisation of an international league.

(i) Cities: Adopting a city based club structure might maximise the interest of a concentrated population. There may be a lesson here from the history of soccer. The authorities of the English Football Association in the nineteenth century envisaged the development of soccer along county cricket lines and established county associations. The fact that club football proved much stronger may in part be due to its foundation on concentrated urban support.

(ii) Regions: Basing clubs around broadly defined regions would allow teams to play at a variety of grounds, picking up revenue by playing occasional matches in areas of lesser support and avoiding feelings of exclusion in areas that would not otherwise have teams.

Given these dimensions, the problem is to decide the location of the clubs. In practice this could be achieved through a franchise system and allowing locations (or entrepreneurs adopting a particular location) to bid. However, since the value of each franchise depends on who else is admitted, it might require a complex and possibly fallible auction design to internalise the impact on other franchises of victory by particular other locations.

In cricket, more than in any sport, the financial backing for the game derives either from very large but very poor populations or from relatively small but very rich populations. Table 1 , showing the population and gross domestic product per head for the five biggest cricket nations illustrates the point.

Table 1: Population, Gross Domestic Product (GDP) and GDP per head for the five largest cricket nations (1999)

\begin{tabular}{l|rrrr}
\hline Country & Population & \multicolumn{2}{c}{ GDP Billion $\$$} & GDP Per Head \$ \\
\hline INDIA & 995 & 443 & 445 \\
PAKISTAN & 136 & 60 & 440 \\
UNITED KINGDOM & 58 & 1437 & 24715 \\
SOUTH AFRICA & 43 & 131 & 3033 \\
AUSTRALIA & 19 & 395 & 20695 \\
\hline
\end{tabular}

Source: IMF

India has fifty times the population of Australia, and one fiftieth of the GDP per head. While India's GDP and Australia's population is rapidly growing, it seems inevitable that a large gap will remain for both measures into the foreseeable future. As things stand, cricket is sufficiently popular in Australia that one might expect that a club based in Sydney or Melbourne could generate a larger income than one based in Mumbai or Delhi. However, this need not be the case. The increasingly affluent middle class of India is several times the population of Australia and even if only the richest $2 \%$ of the population can afford to attend matches, that still gives a potential support base equal to the that of Australia. Moreover, the sale of broadcast rights for an Indian based team might well produce a large income from such an enormous hinterland. 
Similar arguments can be raised in respect of Pakistan, and even South Africa, but it is our view that an international club competition cannot hope to succeed without a presence in each of these five principal cricket nations. On climatic grounds it might also seem attractive to leave the UK out of the picture, as the southern hemisphere have in the case of rugby union, but we believe that the size of the UK market makes such a strategy ultimately implausible.

The choice of locations is inevitably difficult and at this stage somewhat arbitrary. But from an analysis of city sizes it is suggested that the sites should include two from India, two from Australia, two from South Africa, one from Pakistan, either one or two from the UK and possibly one from the Caribbean ${ }^{10}$. These choices reflect not only city sizes but the intensity of support for the game. For example, it is inevitable that Australia, as the world's strongest cricketing nation, and one of its wealthiest, and that India, as the most populous (and the country with the fewest alternative popular sports), will both have an above average number of teams. Whether the UK or South Africa should have two teams seems more debatable. The UK is a bigger market, but support is probably more intense in South Africa.

Table 2. Cities with populations in excess of two million people. Eight candidate sites for the World Cricket League starred.

\begin{tabular}{l|llll}
\hline World Rank & Name & Population & Country & \\
\hline 6 & Mumbai (Bombay) & 17850000 & India & $*$ \\
14 & Calcutta & 12900000 & India & $*$ \\
16 & Karachi & 12100000 & Pakistan & $*$ \\
17 & London & 11800000 & Great Britain & $*$ \\
19 & Delhi & 11500000 & India & \\
34 & Chennai (Madras) & 6600000 & India & \\
35 & Hyderabad & 6500000 & India & \\
36 & Lahore & 6350000 & Pakistan & \\
40 & Johannesburg & 5700000 & South Africa & $*$ \\
43 & Bangalore & 5500000 & India & \\
62 & Ahmadabad & 4150000 & India & \\
68 & Sydney & 4050000 & Australia & $*$ \\
85 & Pune (Poona) & 3400000 & India & \\
90 & Melbourne & 3300000 & Australia & $*$ \\
94 & Cape Town [Kapstadt] & 3100000 & South Africa & $*$ \\
119 & Birmingham & 2600000 & Great Britain & \\
121 & Rawalpindi & 2600000 & Pakistan & \\
130 & Lucknow & 2500000 & India & \\
131 & Manchester & 2500000 & Great Britain & \\
134 & Kanpur & 2450000 & India & \\
149 & Faisalabad (Lyallpur) & 2250000 & Pakistan & \\
150 & Surat & 2250000 & India & \\
161 & Jaipur & 2100000 & India & \\
167 & Leeds & 2050000 & Great Britain & \\
169 & Nagpur & 2050000 & India & \\
\hline
\end{tabular}

Source: Th. Brinkhoff: Principal Agglomerations and Cities of the World, http://www.citypopulation.de, 4.6.00

\footnotetext{
${ }^{10}$ It is difficult to think of a Caribbean city which could support a team if a city-based structure were adopted. However, on a regional basis the idea would be more attractive, particularly if games played also in North America could attract support from the large expatriate Indian communities there.
} 


\section{(c) Format}

To be successful a world league will have to offer a format that attracts spectators, in contrast with most three- or four-day domestic cricket. We think that this inevitably requires the adoption of the one-day version of the game. Games will have to be played at weekends or in the evenings when the fans can attend, but in fact many of these reforms have already been widely accepted within the cricket world. It may be possible to play the longer, more traditional, version of the game for special occasions, long holiday breaks, season openers and so on- but these would be essentially one-offs.

Matches would be played in all cricket playing areas of the world but we believe that for this to work matches played within a region will need always to involve at least one local team. While fans of Karachi may want to see their team play the stars of Australia it is doubtful whether they could they be relied upon to attend matches between, say, Sydney and Melbourne played in their city. To the extent that the teams would hire players from all over world, these might indeed include some Pakistani stars, but this could never be guaranteed and would be unlikely to compensate for the direct interest of local fans. Thus we think that a league style "home and away" format will be required

Scheduling of matches is a critical issue and one important constraint on tournament structure is climate. Cricket cannot be played properly in the rain, and it cannot be played well in extreme cold. Table 3 provides monthly climatic data for the eight cities suggested above as potential locations. Scheduling a tournament for such a diverse set of locations will inevitably be difficult. While temperature is not the main problem at most times for most of the proposed locations apart from London, it is necessary to avoid rainy seasons. Temperature considerations rule out London in the northern winter, while rainfall rules out India in the late northern summer.

Again we suggest two options:

(i) Rolling format:

It would be convenient to adopt a tournament structure that involved moving from location to location through the season. The competition could start in Australia in Nov/Dec during which time the Australian teams would play their home matches against the non-Australasian teams and their local opponents. It could then move to India/Pakistan in Jan/Feb, on to South Africa in Mar/Apr and conclude in England in May/Jun (with a possible visit to America if a Caribbean based team were included). The competition would not need to be drawn out - it could be in four concentrated spells. Perhaps there could also be playoffs and a final in London at the end. Such a scheme would minimise the otherwise massive requirement for travel. It could also encourage mobility between teams since the whole competition would travel as a bloc and joining a foreign team would not necessitate spending more time playing abroad than players for teams of their own nationality.

(ii) Continuous format

An alternative format would concentrate the whole tournament into a single brief period of, say, three months. This could encourage interest in the tournament and the NFL in north America has proven that a very successful format can be played over little more than four months. Inspection of Table 3 suggests that the most reasonable prospect of uninterrupted play would be the period March, April and May, although early matches in London could be 
decidedly chilly and the later matches in Calcutta could be a trifle damp. Overall, however, climate need not be an obstacle to such a concentrated competition. With eight teams a schedule where each team played each of its rivals four times over the three month period would yield a 28 match schedule and a game roughly every three days, leaving time for recovery and travel. Playing squads of around twenty for each team would and a rotation system require each player to appear no more than once a week on average.

\section{Organisational structure and control for a new competition}

The motivating thought behind our proposal for a new international club competition is the need to give the top players a greater stake in the game through higher salaries, comparable with other significant international sports. To do this competition between the clubs for the services of the players is essential, since this is the process by which salaries are bid up. The problem with Test Match cricket is that this competition is by definition absent- players play for their country.

Strong clubs must be run as commercial enterprises- they must have incentives to attract fans and generate revenues. Such a league might materialise through the actions of entrepreneurs not currently involved in the administration of cricket if the market is left to its own devices, just as World Series Cricket emerged as a natural reaction to the failure of international cricket to modernise in the 1970s. However, we think it would be better for cricket as a whole if the competition we envisage were introduced under the auspices of the governing bodies of cricket, in particular the ICC with the support of the national associations. There are several reasons for this:

(i) An independently organised international club league might turn out to be very unbalanced. A degree of competitive balance is necessary to make an attractive competition, but the experience from other leagues shows that a strong central control of the league rules is necessary to ensure that such a balance is maintained. This leading role can be fulfilled by the ICC.

(ii) To ensure that salaries are in fact bid up through competition it will be necessary to prevent collusion among the owners. This protection can be provided through the sanction of the ICC. The ICC or its representatives might explicitly maintain rules such as a requirement that at least a certain percentage of each team should consist of foreign players, not least to ensure that that players from outside the countries possessing a team have an opportunity to play.

(iii) If the new competition were to sit comfortably beside the current structure of Test match cricket it would be necessary to co-ordinate time slots and so on. International soccer works well because, by and large, club soccer does not compete with the representative game due to the overall control of the national authorities.

We propose that the structure of the league should be as follows:

(1) The Central Organisation (CO) should be appointed by the ICC to oversee the proposed World Cricket League (WCL). The functions of the $\mathrm{CO}$ are:

(i) To manage the sale of franchises to business interests in the cities selected on the basis of providing a balanced competition 
(ii) To oversee the sale of broadcast rights and co-ordinate promotional activities for the league (ensuring consistency in merchandising and so on). A significant fraction of these revenues to be allocated as a prize for the winning team, to provide high powered incentives for the participating teams.

(iii) To impose limited redistribution of income if a significant degree of competitive imbalance emerges. The right to tax on this basis must be strictly limited to some fraction of total revenues in order to ensure that franchise owners have the right incentive to maximise revenues.

(iv) To withdraw and reallocate franchises in clear cases of failure.

(v) To determine the expansion of the league, either by the addition of new teams to the existing structure, or by the creation of a second division with promotion and relegation.

(vi) To ensure that the scheduling of the WCL does not interfere with the scheduling of Test Match cricket and, as far as is possible, domestic cricket competitions.

(vii) To limit the power of clubs to stockpile players- a roster limit of, say, 25 players, might be imposed.

(2) Individual franchise owners will have the following rights:

(i) To retain locally generated revenues (including ticket sales, local sponsorship deals, catering and so on) up to some agreed fraction of the total, probably in the region of $75 \%$.

(ii) To hire players in the market subject to the constraint that at least a certain percentage of players are foreigners. Movements of players between teams to be fixed according to some transfer rules. A transfer window might apply, such that transfers cannot take place during the WCL season.

(iii) To negotiate match schedules with the CO.

We believe that this structure would balance the interests of the players, the national game, the international governing body and the interests of the newly created clubs, without damaging the incentives of the new clubs to create a competitive and attractive league.

\section{Conclusions}

Cricket is a popular sport, and therefore it has the potential to sustain a successful international circuit such as Test Match cricket as well as domestic competition. However, to realise its full potential requires a structure that draws money into the game. Test Match cricket cannot do this on its own, and we believe the gambling scandals that have been so damaging to the game's reputation are simply a symptom of that failure. Rather than deal only with the symptoms, we propose a way of dealing with the underlying disease, which is the absence of a strong club competition which is a characteristic of all the successful team sports.

We suggest that a club competition limited to a select number of international locations could generate considerable fan interest. Were such a competition to be successful, it would result in increasing competition for player services, higher wages and ultimately give the players a greater personal stake in the future of the game. Moreover, we believe that an international club competition could prove a significant revenue generator for world cricket. In this paper we have suggested that in an ideal world such a competition would operate most efficiently if 
sanctioned and ultimately controlled by the ICC. However, if this does not happen, we also think it quite likely that such a competition would generate itself spontaneously.

With cricket in crisis, the ICC holds an effective mandate for reform. By introducing new forms of competition it may be able to wipe clean the taints of the past and strengthen existing forms such as Test cricket. 
Table 3: Monthly temperature and rainfall for selected cities

\begin{tabular}{|c|c|c|c|c|c|c|c|c|c|c|c|c|c|}
\hline City & Variable & Jan & Feb & Mar & Apr & May & Jun & Jul & Aug & Sep & Oct & Nov & Dec \\
\hline Bombay & Max temp C & 28 & 28 & 30 & 32 & 33 & 31 & 30 & 29 & 30 & 32 & 32 & 30 \\
\hline Calcutta & Max temp C & 26 & 29 & 34 & 36 & 35 & 34 & 32 & 32 & 32 & 32 & 29 & 26 \\
\hline Cape Town & Max temp C & 26 & 27 & 25 & 23 & 20 & 18 & 18 & 18 & 19 & 21 & 24 & 25 \\
\hline Johannesburg & Max temp C & 26 & 25 & 24 & 21 & 19 & 16 & 17 & 19 & 23 & 24 & 24 & 25 \\
\hline Karachi & Max temp C & 25 & 26 & 29 & 32 & 34 & 34 & 33 & 31 & 31 & 33 & 31 & 27 \\
\hline London & Max temp C & 7 & 7 & 10 & 12 & 16 & 20 & 22 & 22 & 19 & 15 & 10 & 8 \\
\hline Melbourne & Max temp C & 26 & 26 & 24 & 20 & 17 & 14 & 13 & 15 & 17 & 20 & 22 & 24 \\
\hline Sydney & Max temp C & 26 & 26 & 25 & 23 & 20 & 17 & 17 & 18 & 20 & 22 & 24 & 26 \\
\hline Bombay & Min temp C & 19 & 20 & 22 & 24 & 26 & 26 & 25 & 25 & 24 & 24 & 23 & 20 \\
\hline Calcutta & Min temp C & 13 & 15 & 20 & 24 & 25 & 26 & 26 & 26 & 26 & 23 & 18 & 13 \\
\hline Cape Town & Min temp C & 16 & 16 & 14 & 12 & 9 & 8 & 7 & 8 & 9 & 11 & 13 & 15 \\
\hline Johannesburg & Min temp C & 15 & 14 & 13 & 10 & 7 & 4 & 4 & 6 & 9 & 11 & 13 & 14 \\
\hline Karachi & Min temp C & 13 & 14 & 19 & 23 & 26 & 28 & 27 & 26 & 25 & 22 & 18 & 14 \\
\hline London & Min temp C & 1 & 1 & 2 & 4 & 7 & 10 & 12 & 12 & 10 & 7 & 4 & 2 \\
\hline Melbourne & Min temp C & 14 & 14 & 13 & 11 & 9 & 7 & 6 & 7 & 8 & 9 & 11 & 13 \\
\hline Sydney & Min temp C & 18 & 19 & 17 & 14 & 11 & 8 & 7 & 8 & 10 & 13 & 15 & 17 \\
\hline Bombay & Rain mm & 4 & 2 & 1 & 4 & 17 & 484 & 616 & 340 & 264 & 65 & 14 & 2 \\
\hline Calcutta & Rain mm & 9 & 30 & 35 & 45 & 140 & 272 & 125 & 328 & 253 & 114 & 21 & 5 \\
\hline Cape Town & Rain mm & 15 & 17 & 20 & 41 & 69 & 93 & 82 & 77 & 40 & 30 & 14 & 17 \\
\hline Johannesburg & Rain mm & 125 & 90 & 91 & 54 & 13 & 9 & 4 & 6 & 27 & 72 & 117 & 105 \\
\hline Karachi & Rain mm & 13 & 10 & 8 & 3 & 3 & 18 & 81 & 41 & 13 & 0 & 3 & 5 \\
\hline London & Rain mm & 62 & 41 & 49 & 46 & 47 & 50 & 45 & 48 & 60 & 60 & 67 & 65 \\
\hline Melbourne & Rain mm & 48 & 47 & 52 & 58 & 58 & 50 & 49 & 51 & 59 & 68 & 59 & 59 \\
\hline Sydney & Rain mm & 100 & 111 & 127 & 109 & 98 & 129 & 69 & 80 & 60 & 76 & 83 & 77 \\
\hline \multicolumn{2}{|c|}{ Standard deviation of max temp } & 7 & 7 & 7 & 8 & 8 & 8 & 8 & 7 & 6 & 7 & 7 & 7 \\
\hline \multicolumn{2}{|c|}{ Standard deviation of min temp } & 6 & 6 & 6 & 8 & 9 & 10 & 10 & 9 & 8 & 7 & 6 & 5 \\
\hline \multicolumn{2}{|c|}{ standard deviation of rainfall } & 46 & 39 & 43 & 33 & 47 & 163 & 198 & 133 & 101 & 34 & 41 & 40 \\
\hline \multicolumn{2}{|c|}{ Average max temp } & 24 & 24 & 25 & 25 & 24 & 23 & 23 & 23 & 24 & 25 & 24 & 24 \\
\hline \multicolumn{2}{|c|}{ Average min temp } & 14 & 14 & 15 & 15 & 15 & 15 & 14 & 15 & 15 & 15 & 14 & 13 \\
\hline \multicolumn{2}{|c|}{ Average rainfall } & 47 & 44 & 48 & 45 & 56 & 138 & 134 & 121 & 97 & 61 & 47 & 42 \\
\hline
\end{tabular}




\section{References}

Birley, D. (1999) A Social History of English Cricket, Aurum Press, London.

Bose, M. (2001) “A Game in Shame” in: G. Wright (ed) Wisden Cricketer's Almanack 2001, John Wisden and Co, London, 17-28.

Craig, S. (2001) "It's Not Cricket" History Today 51, 6, 40-41.

Central Bureau of Investigation (2000) Report on Cricket Match Fixing and Related Malpractices, New Delhi

Condon, Sir P. (2001) Report on Corruption in International Cricket, Anti-Corruption Unit, International Cricket Council, London.

England and Wales Cricket Board Limited (1999) Report and Financial Statements 31 December 1999, London.

King, Judge E. L. (2000) Commission of Inquiry into Match Fixing and Related Matters: Interim Report, Cape Town.

O'Regan, R. (1998) Player Conduct Inquiry Report, Australian Cricket Board, Jolimont, Victoria.

Qayyum, Justice M. M. (1998) Report of Judicial Commission Pakistan Cricket Board, Lahore.

Underdown, D. (2000) Start of Play: Cricket and Culture in Eighteenth Century England Allen Lane, London. 